\title{
Process intensification for obtaining a cannabidiol intermediate by photooxygenation of limonene under continuous-flow conditions
}

\author{
Anderson R. Aguillón, ${ }^{a}$ Raquel A. C. Leão, ${ }^{\mathrm{a}, \mathrm{b}}$ Kleber Thiago de Oliveira, ${ }^{\mathrm{b}}$ \\ Timothy John Brocksom, ${ }^{b}$ Leandro S. M. Miranda, ${ }^{a}$ Rodrigo O. M. A. de Souza ${ }^{* a, c}$ \\ ${ }^{a}$ Biocatalysis and Organic Synthesis Group, Chemistry Institute, Federal \\ University of Rio de Janeiro, Rio de Janeiro, Brazil, 21941909 \\ ${ }^{b}$ Departamento de Química, Universidade Federal de São Carlos, São \\ Carlos, SP, 13565-905, Brazil. \\ ${ }^{c}$ Faculdade de Farmácia, Universidade Federal do Rio de Janeiro, Rio \\ de Janeiro - RJ, 21941-170, University of Rio de Janeiro, CEP: 21941-910, \\ Brazil.
}


SUMARY

1.1 PHOTOCHEMICAL REACTOR FOR BATCH EXPERIMENT 3

2.1 PHOTOCHEMICAL REACTOR FOR FLOW EXPERIMENTS 4

2.1.1 Home-made setup 1 reactor for limonene photo-oxidation 4

2.1.2 Home-made setup 2 reactor for limonene photo-oxidation 6

2.1.3 Home-made setup 3 reactor for limonene photo-oxidation 8

2.1.4 Home-made setup 4 reactor for limonene photo-oxidation $\quad 10$

3.1 EMISSION SPECTRUM OF LEDS AND TPP 15

4.1 CHROMATOGRAPHIC ANALYSIS 17

5.1 OPTIMIZATION BATCH EXPERIMENTS FOR LIMONENE PHOTO-OXIDATION 18

$6.1{ }^{1} \mathrm{H}$ AND ${ }^{13} \mathrm{C}$ NMR SPECTRA 20

7.1 REFERENCES 22 
Batch photo-oxygenation was carried out at in a basic home engineered setup (Figure S1). The homemade batch reactor was projected using an outdoor IP65 microLED White lamp (6500K; 2), a cooler (1) fan to avoid overheating in the top, and a magnetic-stirrer plate device (3) on the button. In batch experiments, the oxygenation of the solution containing the sensitizer and limonene was performed by oxygen bubbling, using a simple rubber balloon ( $1 \mathrm{~atm}$ ) and maintained throughout the reaction time.

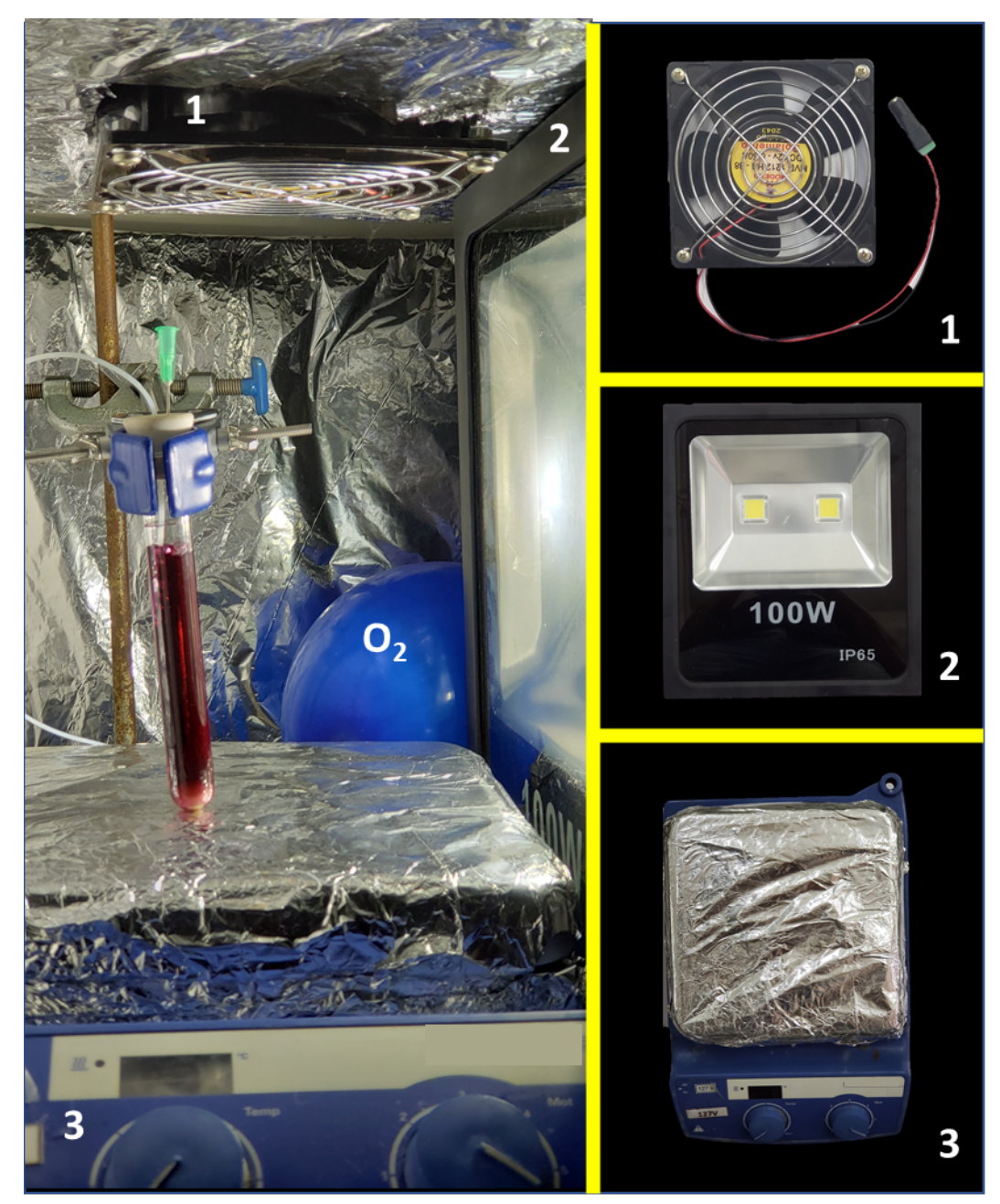

Figure S1. Setup for batch experiments 


\subsection{PHOTOCHEMICAL REACTOR FOR FLOW EXPERIMENTS}

\subsubsection{Home-made setup 1 reactor for limonene photo-oxidation}

To perform the photochemical reactions in a continuous flow regime, a photoreactor with the setup \# 1 (Figure S2) was set up and adapted with a siliconglass microreactor. In our design, a microchip reactor (1000 $\mu \mathrm{L}$, Syrris; 4) was irradiated with an set outdoor white microLED IP65 lamp (100W, 6500K; 1) and a cooler (5) fan to avoid overheating in the top. In the setup 1, the oxygenation of the solution containing the sensitizer and limonene was pumped by high pressure Knauer pump (2), saturated with oxygen through a tube-in-tube membrane reactor (TIT; 3), keeping pressurized at100 psi by using a BPR. 

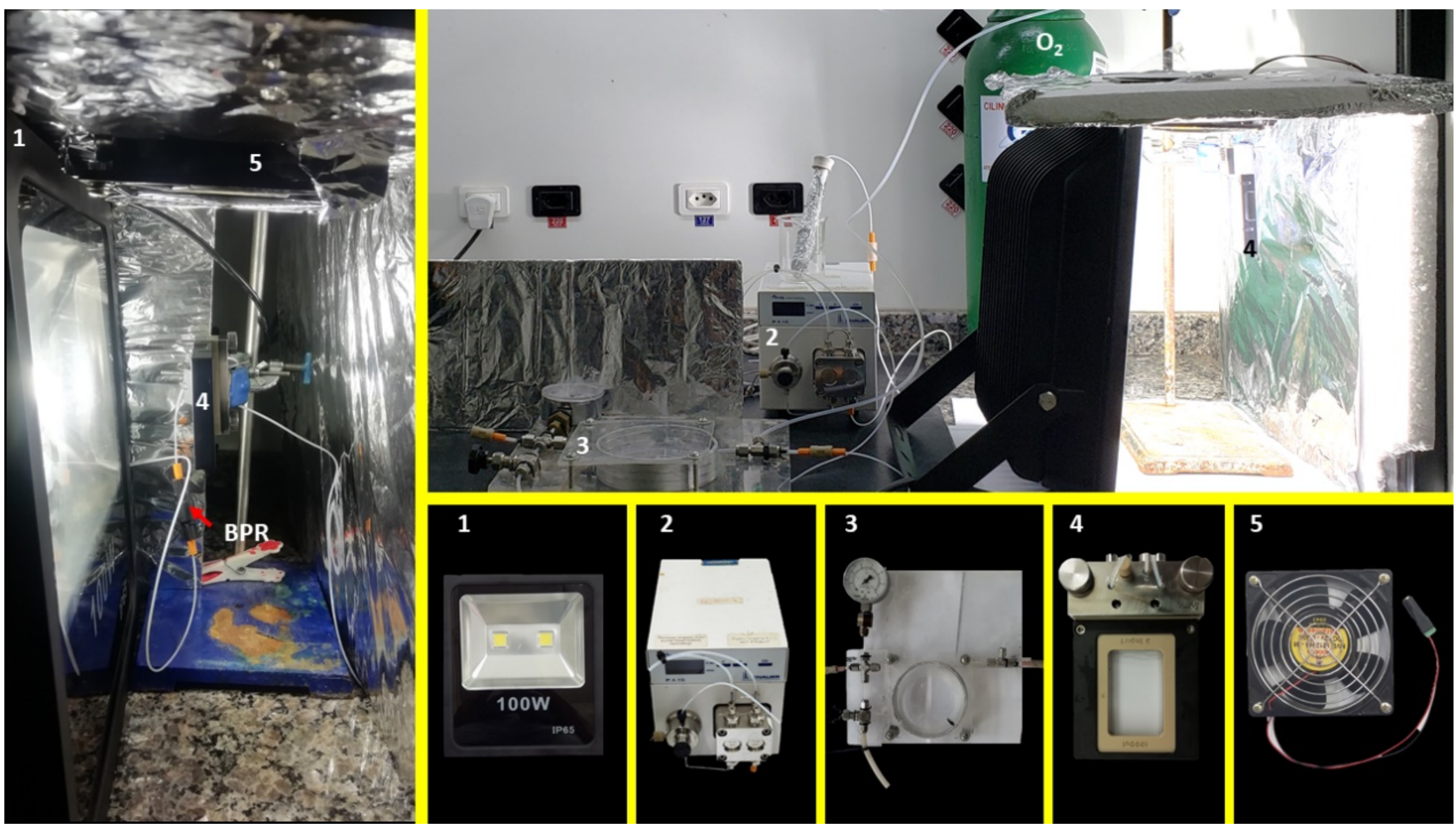

Figure S2. Setup \#1 for photo-oxigenation of limonene using TPP as sensitizer. 


\subsubsection{Home-made setup 2 reactor for limonene photo-oxidation}

To perform the photochemical reactions in a continuous flow regime, a photoreactor with the setup \# 2 (Figure S3) was set up and adapted with a siliconglass microreactor. In our design, a microchip reactor (1000 $\mu \mathrm{L}$, Syrris; 4) was irradiated with set of four microchips blue LED (30W, 6500K; 1) and a cooler (5) fan to avoid overheating in the top. In the setup 1, the oxygenation of the solution containing the sensitizer and limonene was pumped by a high pressure Knauer pump (2), saturated with oxygen through a tube-in-tube membrane reactor (TIT; 3), keeping pressurized the line at 100 psi by using a BPR (6). 


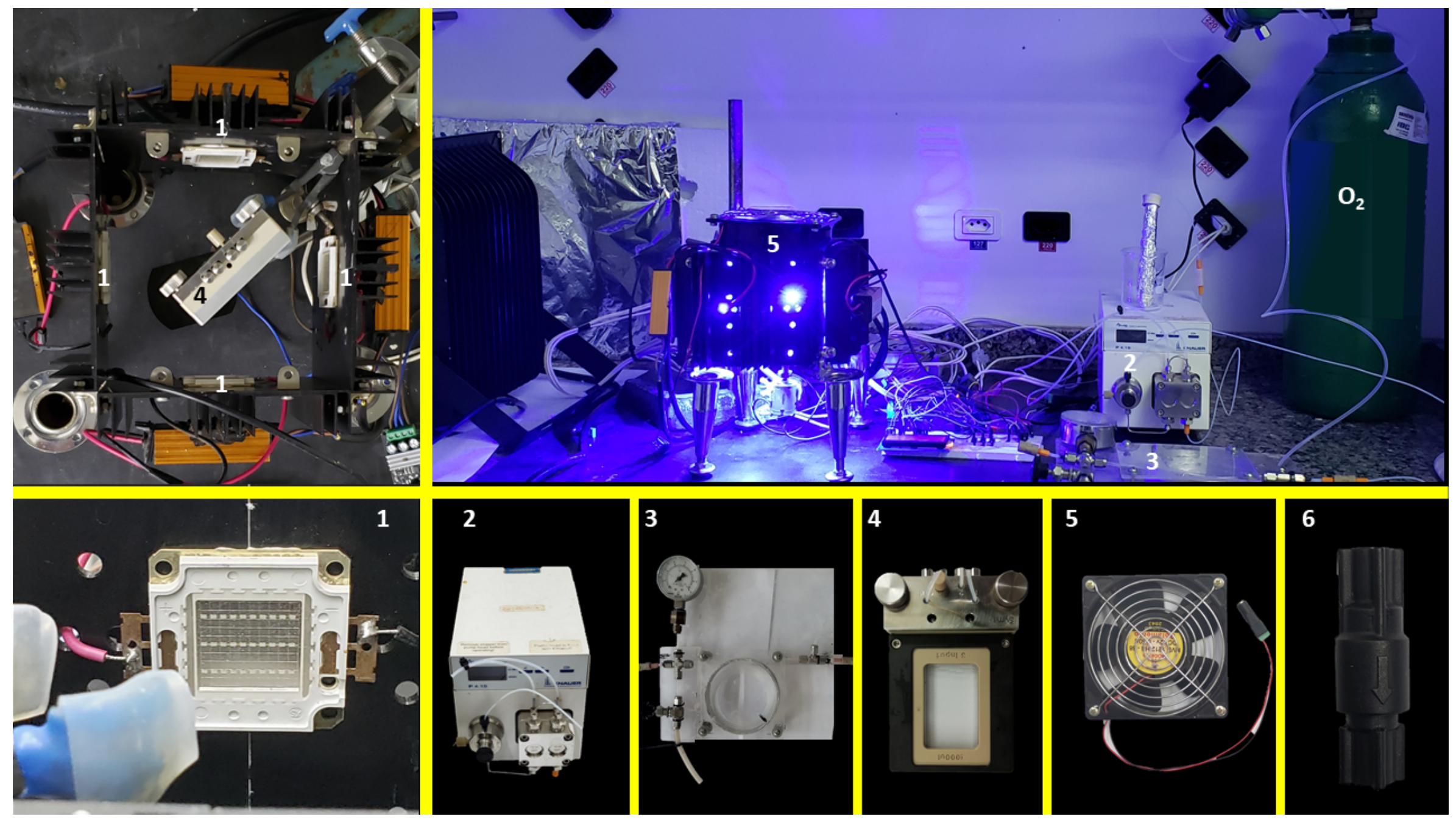

Figure S3 Setup \#2 for photo-oxygenation of limonene using TPP as sensitizer. 


\subsubsection{Home-made setup 3 reactor for limonene photo-oxidation}

To perform the photochemical reactions in a continuous flow regime, a photoreactor with the setup \# 3 (Figure S4) was employed and adapted with a homemade reactor previously detailed by Oliveira and co-workers ${ }^{1,2}$. In our design, a glass tube wrapped with PFA (perfluoroalkoxy polymer) tubing $(12 \mathrm{~m}$, ID:0.065 in and OD: $0.125 \mathrm{in}-30 \mathrm{~mL} ; \mathbf{5}$ ) was irradiated with set of LEDs attached to the reactor walls of aluminium cave, a cooler (3) fan to avoid overheating in the top and base of photoreactor. In the setup 3, the oxygenation of the solution containing the sensitizer and limonene was pumped by high pressure Syrris pump (1), saturated with oxygen through a tube-in-tube membrane reactor (TIT; 2), keeping pressurized the line at 100 psi by using a BPR (4). 

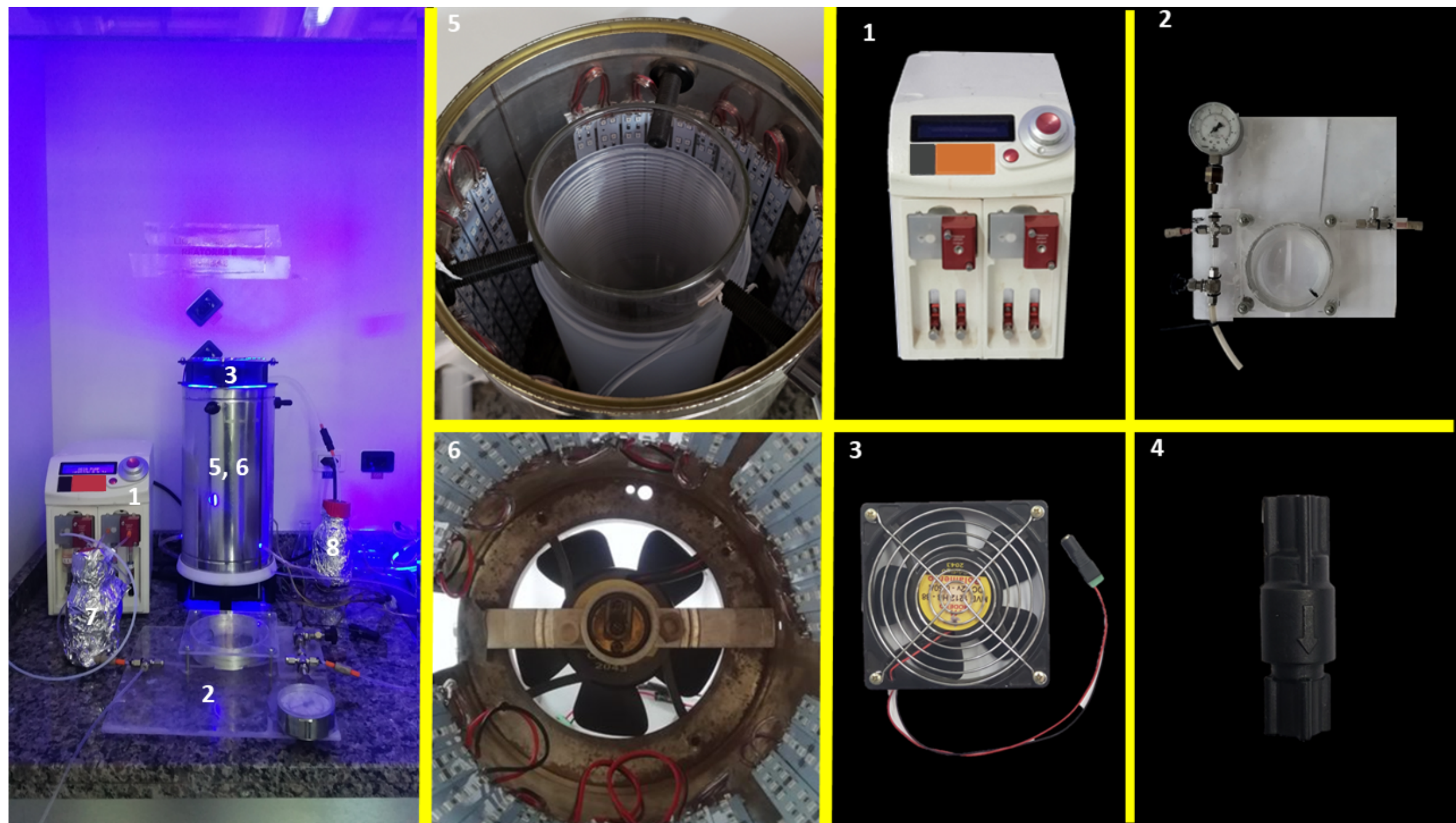

4

Figure S4. Setup \#3 for photo-oxigenation of limonene using TPP as sensitizer. 


\subsubsection{Home-made setup 4 reactor for limonene photo-oxidation}

To perform the photochemical reaction at low temperatures we have used a previously described photoreactor, ${ }^{2}$ using different commercial parts. First, a reagent container (approximately $29 \mathrm{~cm}$ in height and 15 in diameter) was cut and adapted for construction of the photoreactor in continuous flow system (Figure 5). A cylindrical support was attached at the bottom to maintain the reactor of standing and fix a cooler. Three holes were drilled in the top of the reactor to insert the screws to centralize the tubular reactor. Additionally, two holes (approximately 7 and $3 \mathrm{~cm}$ ) were made from opposite sides of the can for the inlet and outlet of all of PFA tubbing that was wrapped in the reactor and the hoses used in the cooling system. At the top of the reactor was placed another cooler (Figure S7).

On the wall of the reactor blue LEDs strips $(110 \mathrm{~W})$ were attached in the cylindrical support (Figure S6 and S7). A glass tube was constructed for the cooling system in which the pumping of the water / ethylene glycol mixture at -20 ${ }^{\circ} \mathrm{C}$ was done using the Chiller. This tube was wrapped with PFA (perfluoroalkoxy polymer) tubing (10.5 m, ID:0.065 in and OD: 0.125 in - Volume $30 \mathrm{~mL}$ ) (Figure S5). Additionally, a heat exchanger which consisting with a cupper coil $(8 \mathrm{~mL})$ cooling the outer with ethanol at $-30{ }^{\circ} \mathrm{C}$ by a second chiller, was added in order to set low temperature at reactor inlet (Figure S8). In the setup 4, the oxygenation of the solution containing the sensitizer and limonene was pumped by high pressure Syrris pump (1), saturated with oxygen through a tube-in-tube membrane reactor (TIT; 2), keeping pressurized at 100 psi by using a BPR (4). 
) .

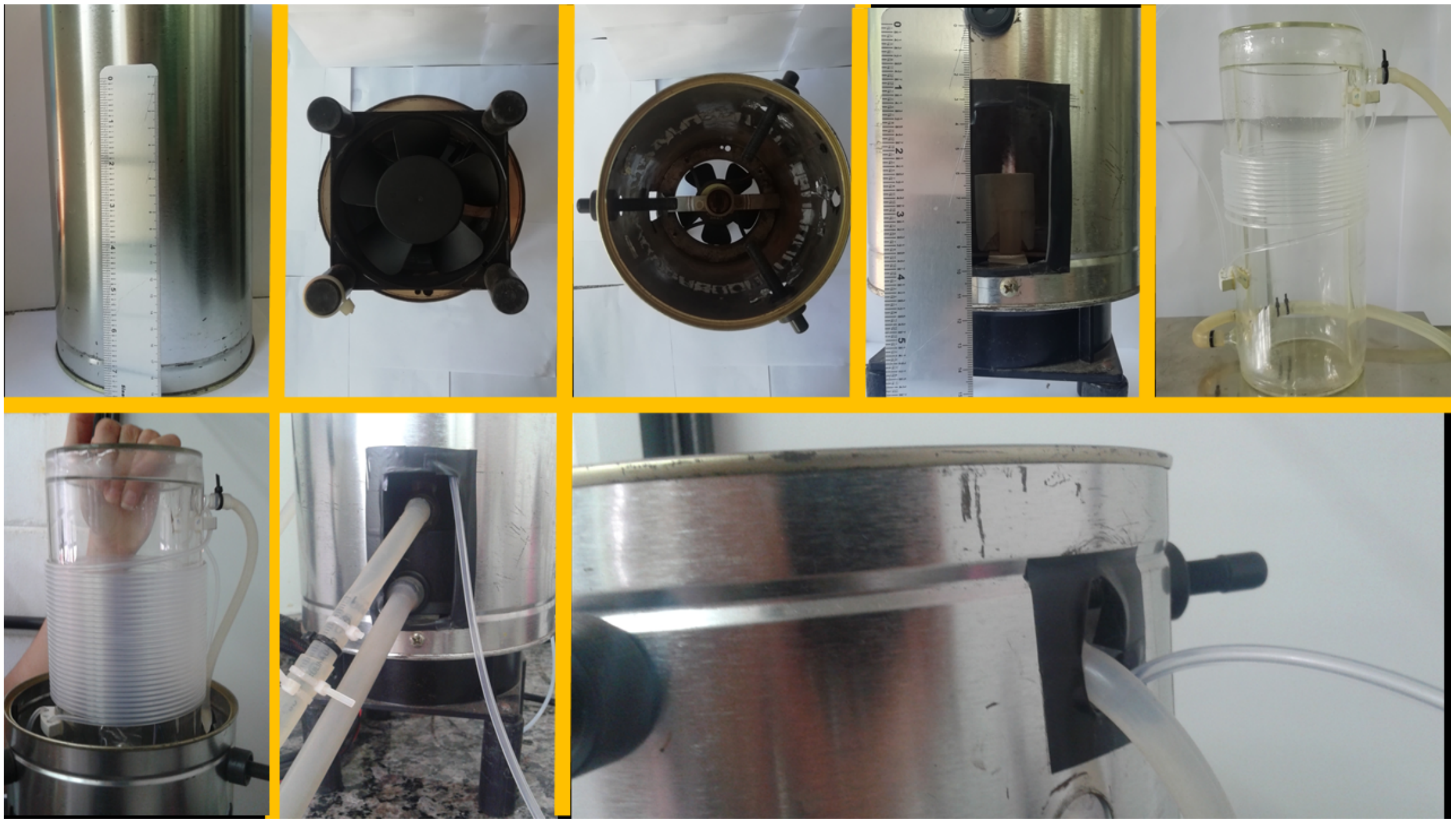

Figure S5. Construction of the photochemical reactor for continuous flow reaction at low temperature 


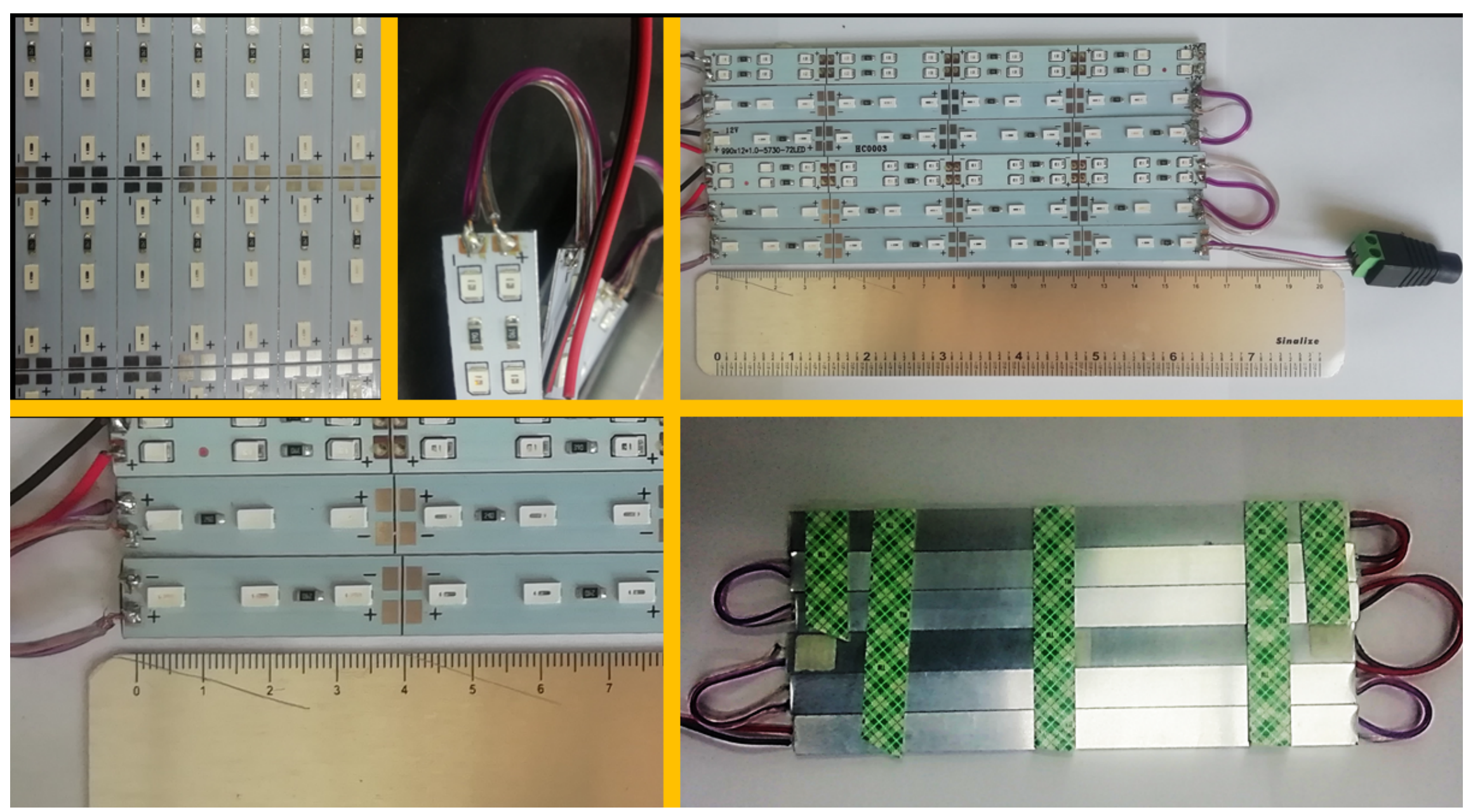

Figure S6 LED assembly for homemade photochemical setup 4 reactor. 


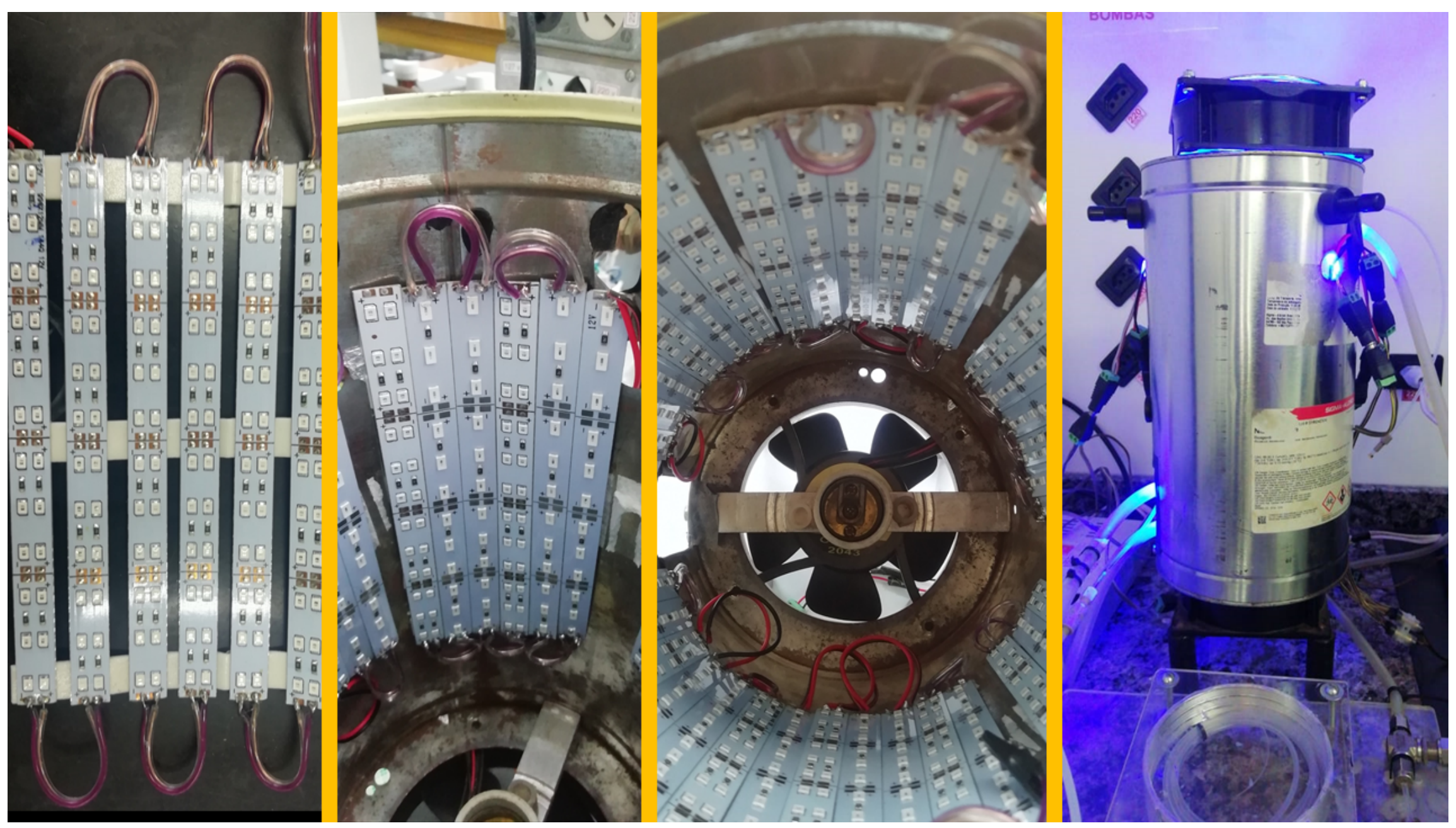

Figure S7 LED attached in the wall of aluminium cave for homemade photochemical setup 4 reactor. 


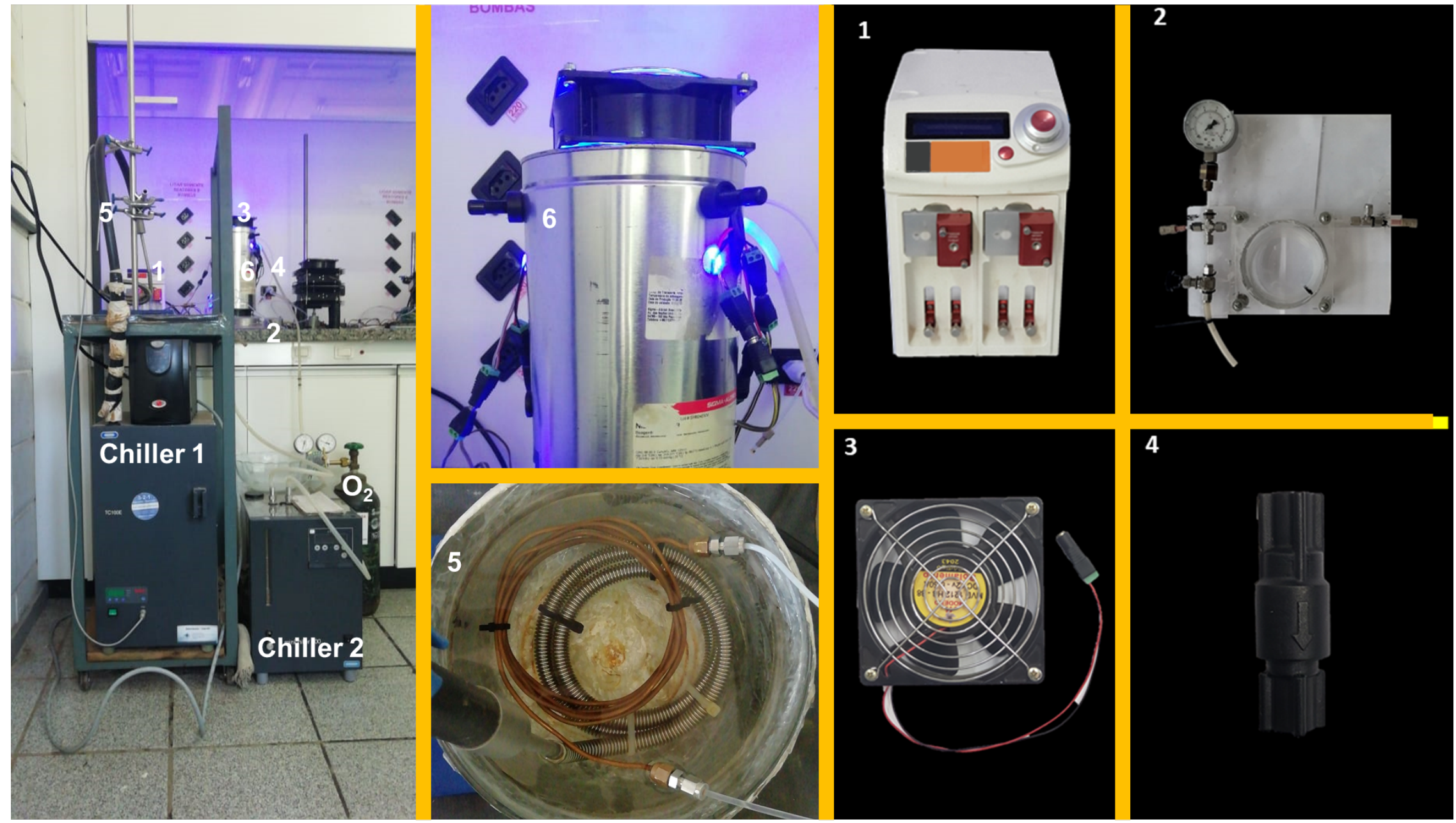

Figure S8 Final assembly of the photochemical reactor and PFA tubular reactor 
$3.1 \quad$ EMISSION SPECTRUM OF LEDS

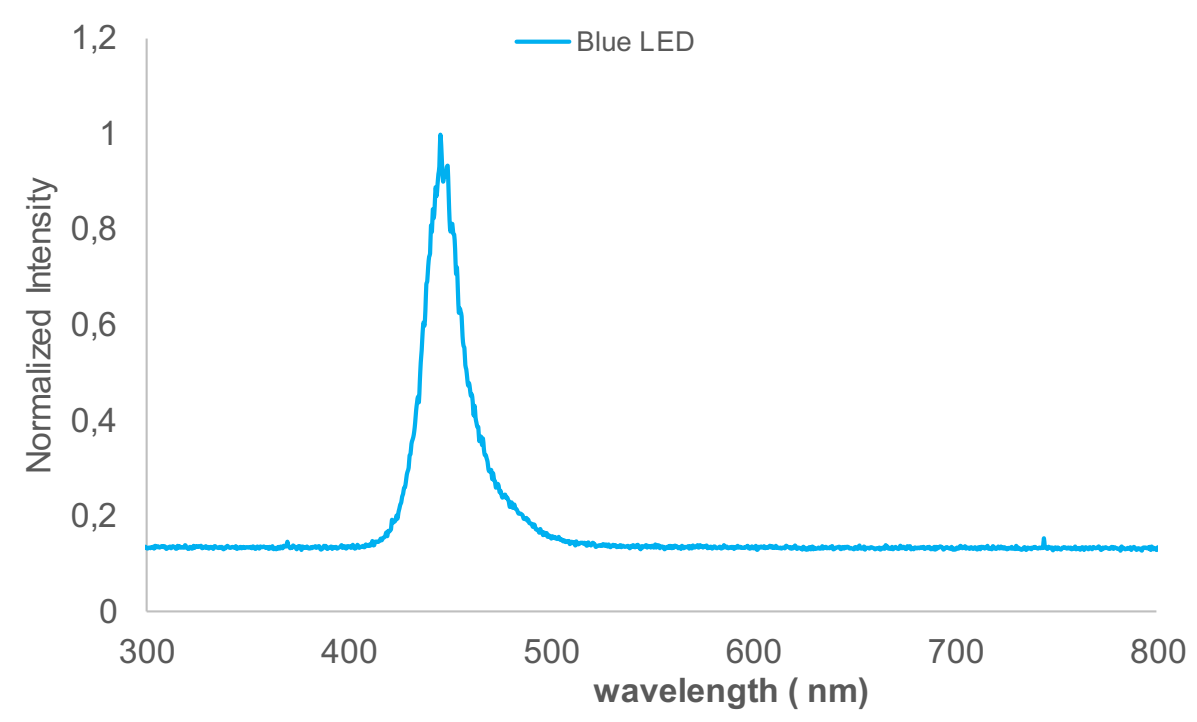

Figure S9 Emission spectrum blue LEDs

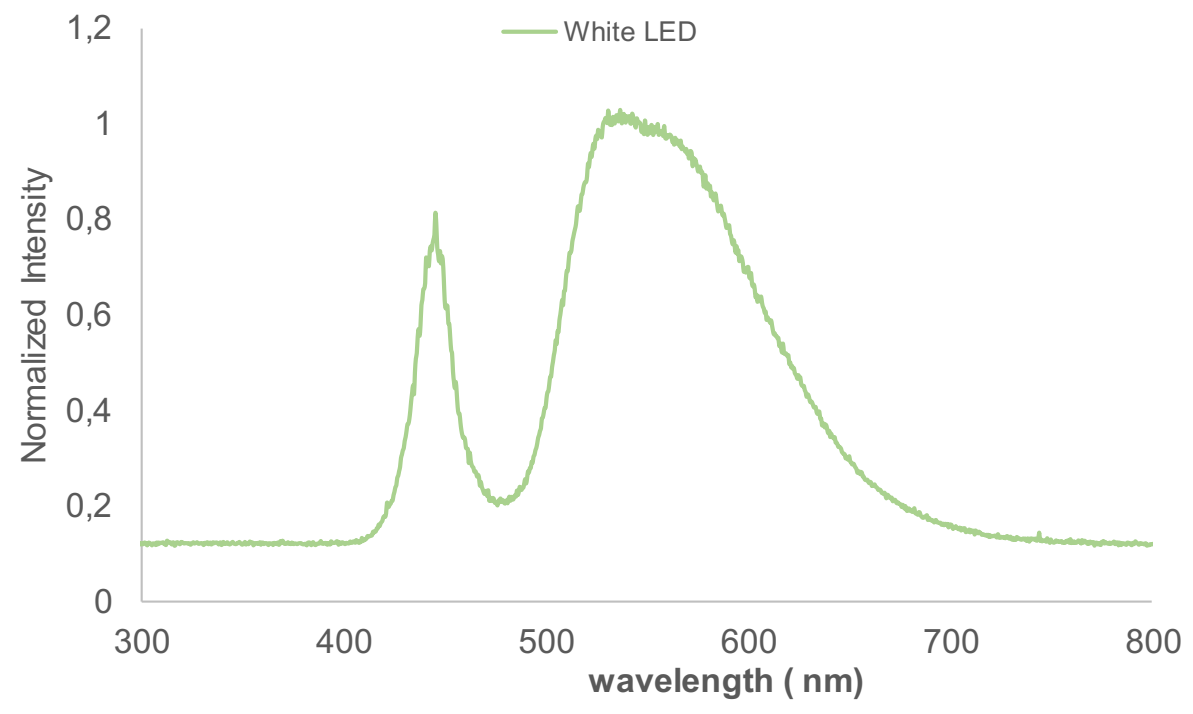

Figure S10 Emission spectrum withe LEDs 


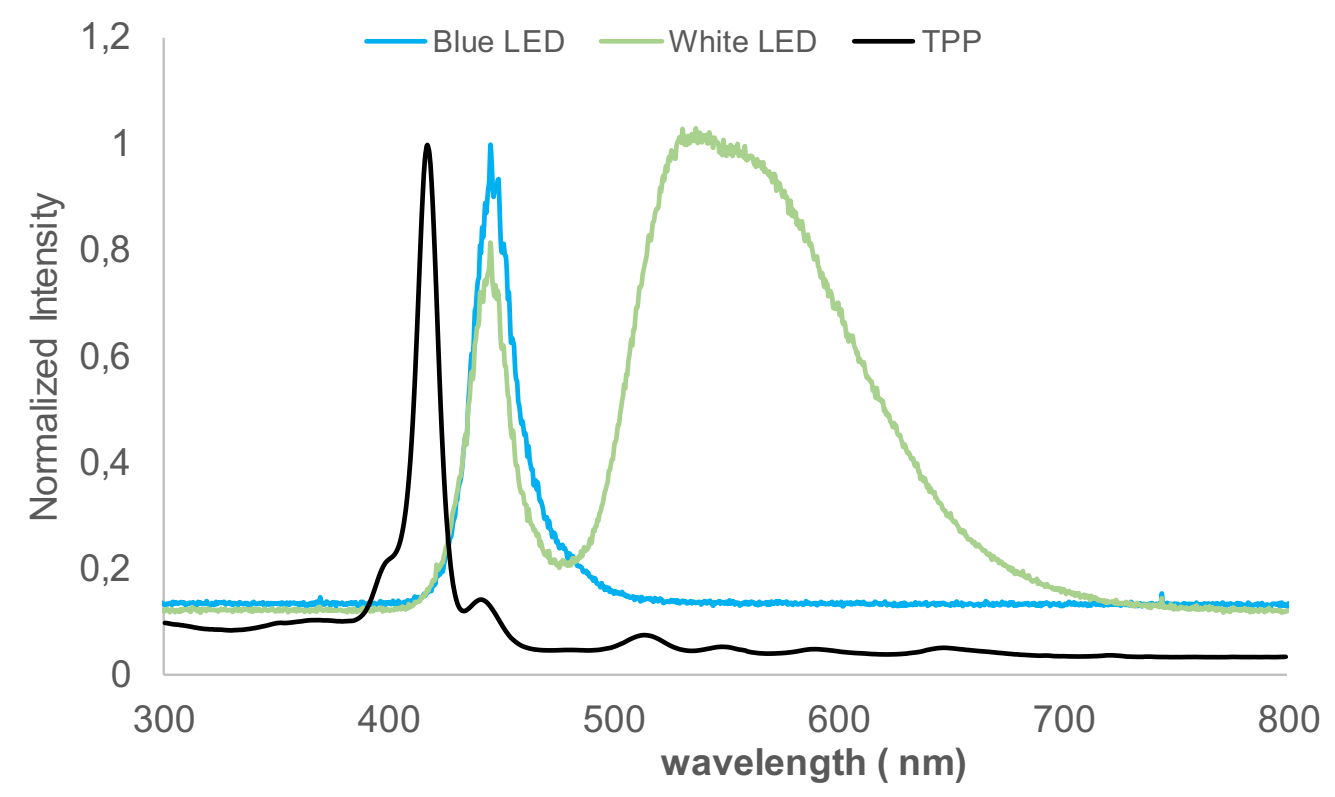

Figure S11 Normalized spectrum profile of LEDs and TPP 


\subsection{CHROMATOGRAPHIC ANALYSIS}

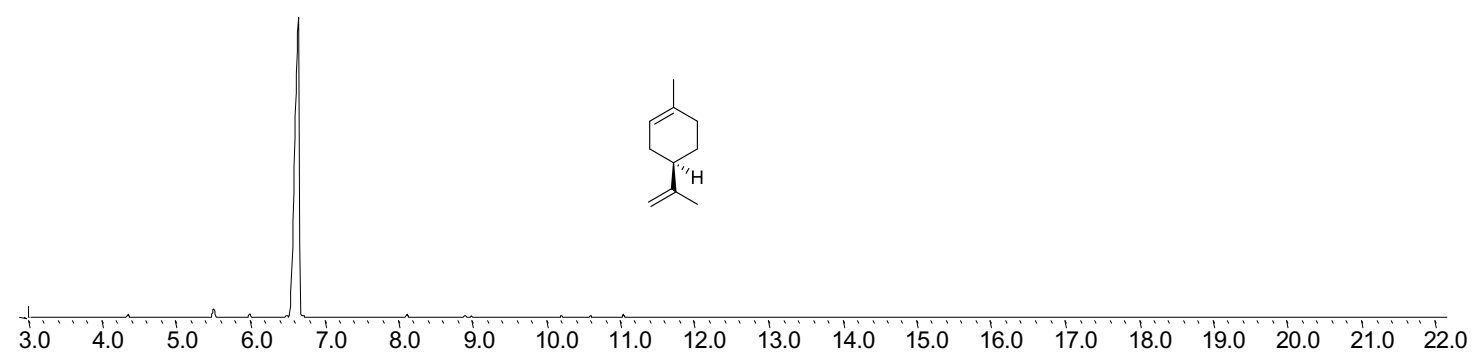

Figure S12. Chromatographic profile of limonene on GC-MS

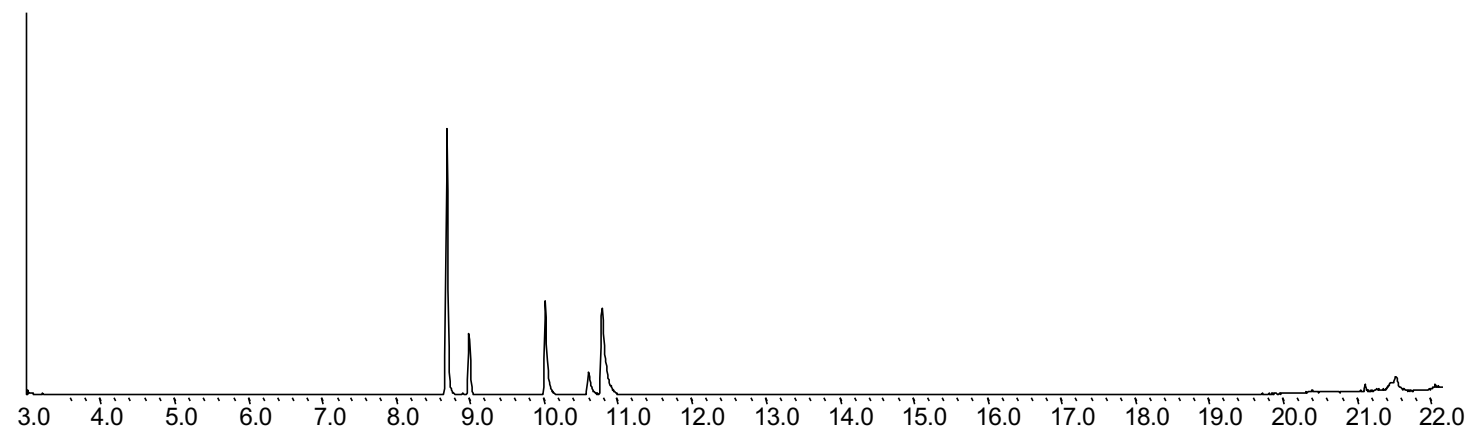

Figure S13. Chromatographic profile of limonene photo-oxidation on GC-MS mediated by TPP.

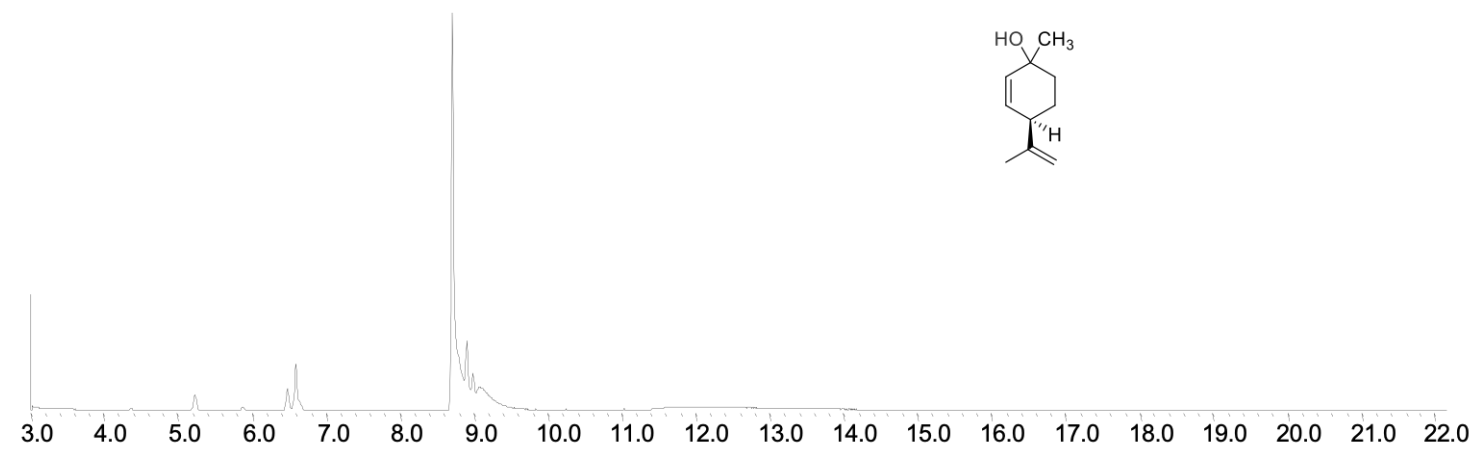

Figure S14.. Chromatographic profile of 1 on GC-MS 


\subsection{OPTIMIZATION BATCH EXPERIMENTS FOR LIMONENE PHOTO-OXIDATION}

Table S1. Sensitizer screening for limonene photo-oxidation

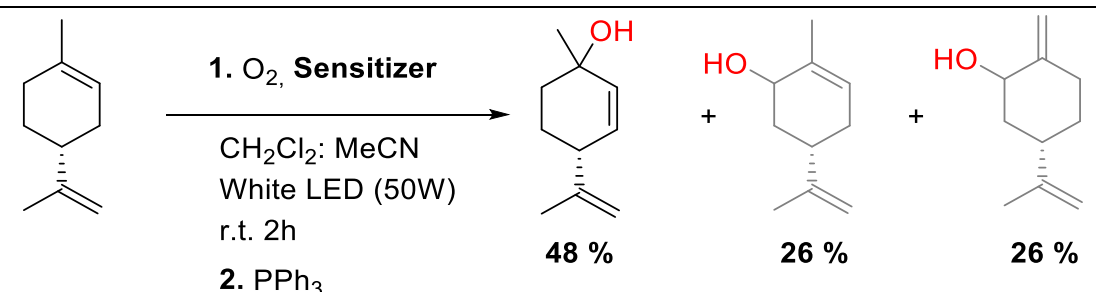

(2)

(1)

(3)

(4)

\begin{tabular}{clcc}
\hline Entry & Sensitizer & Conversion (\%) & Selectivity (\%) \\
\hline 1 & Methylene Blue $^{\mathrm{a}}$ & 23 & 50 \\
2 & Eosin B $^{\mathrm{a}}$ & $>1$ & $>1$ \\
3 & Eosin Y $^{\mathrm{a}}$ & $>5$ & $>1$ \\
4 & Bengal Rose $^{\mathrm{a}}$ & 30 & 46 \\
5 & $\mathrm{TPP}^{\mathrm{b}}$ & 99 & 48 \\
6 & $\left.\mathrm{Ru}_{(\mathrm{bpy}}\right)_{3}\left(\mathrm{PF}_{6}\right)_{2}{ }^{\mathrm{c}}$ & 50 & 43
\end{tabular}

Experimental conditions: 2 (25 mM), Sensitizer $(0,4 \% \mathrm{~mol})$, a) $\mathrm{MeOH}$, b) $\mathrm{CH}_{2} \mathrm{Cl}_{2}$, c) $\mathrm{CH}_{2} \mathrm{Cl}_{2}: \mathrm{MeCN}$ (1:3), LED White lamp $100 \mathrm{~W}, 2 \mathrm{~h}$.

Table S2. Sensitizer screening for limonene photo-oxidation

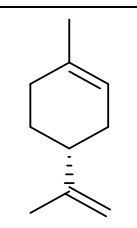

(2)

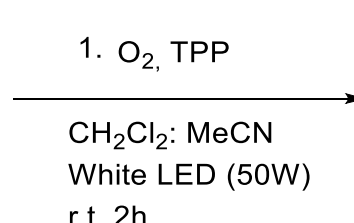

2. $\mathrm{PPh}_{3}$

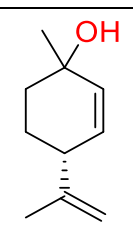

(1)

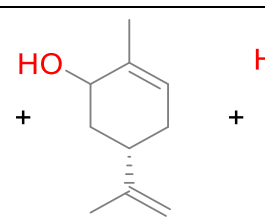

(3)

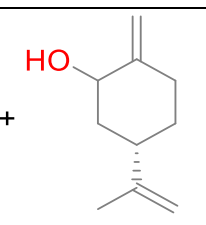

(4)

\begin{tabular}{ccccc}
\hline Entry & Conc.2 (mM) & Solvent & Conv.(\%) & Select(\%) \\
\hline 1 & 25 & $\mathrm{CH}_{2} \mathrm{Cl}_{2}$ & 94 & 46 \\
2 & 25 & $\mathrm{CH}_{2} \mathrm{Cl}_{2}: \mathrm{MeCN}^{\text {a }}$ & 94 & 48 \\
3 & 25 & $\mathrm{MeCN}$ & 40 & 50 \\
4 & 100 & $\mathrm{CH}_{2} \mathrm{Cl}_{2}: \mathrm{MeCN}^{\text {b }}$ & 84 & 48 \\
5 & 400 & $\mathrm{CH}_{2} \mathrm{Cl}_{2}: \mathrm{MeCN}^{\mathrm{a}}$ & 30 & 46
\end{tabular}

Experimental conditions: 2 (25- 400mM), TPP $(0,4 \% \mathrm{~mol})$, LED white lamp $100 \mathrm{~W}, 2 h$. a) $\mathrm{CH}_{2} \mathrm{Cl}_{2}: \mathrm{MeCN}(1: 3) ;$ b) $\mathrm{CH}_{2} \mathrm{Cl}_{2}: \mathrm{MeCN}(1: 9)$, 


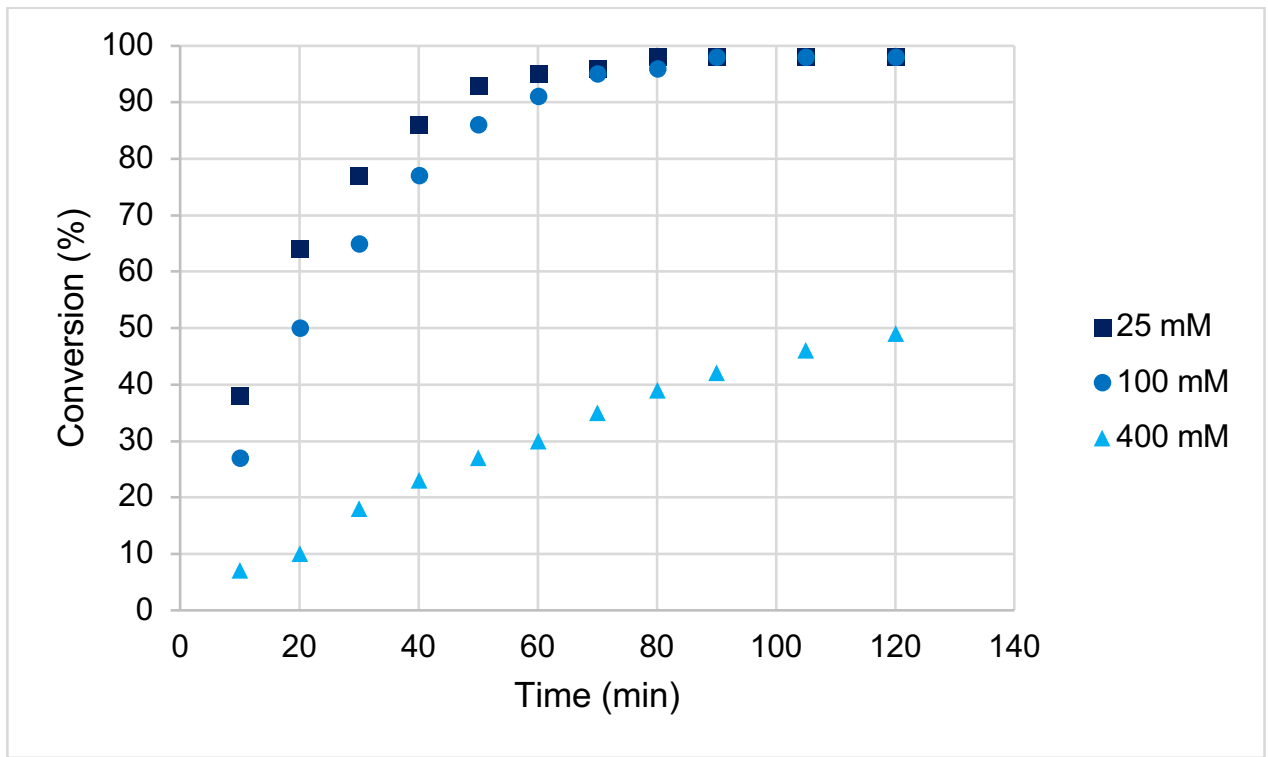

Figure S15. Conversion profile of limonene photo-oxidation using different concentrations. 
6.1 $\quad{ }^{1} \mathrm{H}$ AND ${ }^{13} \mathrm{C}$ NMR SPECTRA

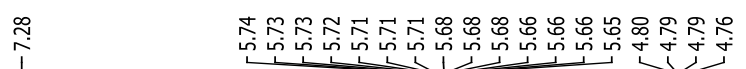

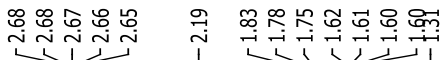

${ }^{1} \mathrm{H}-\mathrm{NMR}\left(500 \mathrm{MHz}, \mathrm{CDCl}_{3}\right) \delta 5.74-5.70(\mathrm{~m}, 1 \mathrm{H}), 5.69-5.65(\mathrm{~m}$, $1 \mathrm{H}), 4.80-4.78(\mathrm{~m}, 1 \mathrm{H}), 4.76(\mathrm{~s}, 1 \mathrm{H}), 2.70-2.64(\mathrm{~m}, 1 \mathrm{H}), 1.87$ $1.82(\mathrm{~m}, 1 \mathrm{H}), 1.79$ (dd, J = 11.0, $5.3 \mathrm{~Hz}, 1 \mathrm{H}), 1.75$ (s, 3H), 1.62 $(\mathrm{m}, 2 \mathrm{H}), 1.31(\mathrm{~s}, 3 \mathrm{H})$.
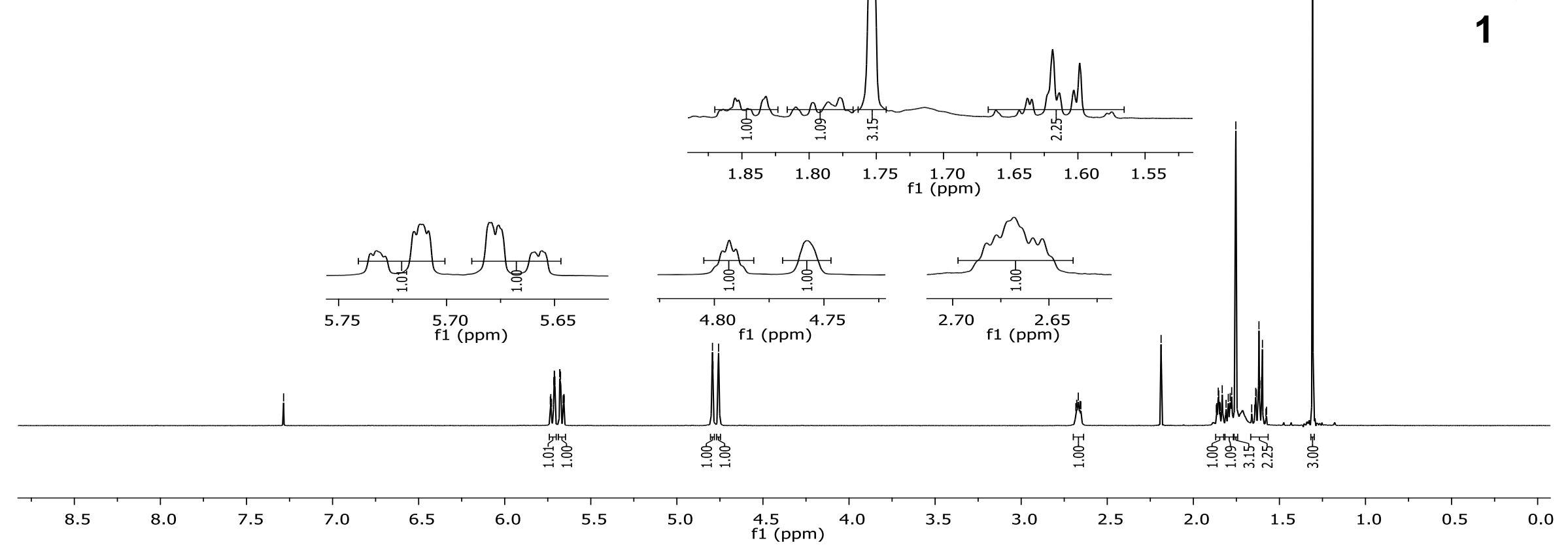

Figure S16 ${ }^{1} \mathrm{H}$ NMR spectra of $p$-mentha-2,8-dien-1-ol (1) in $\mathrm{CDCl}_{3}$ 


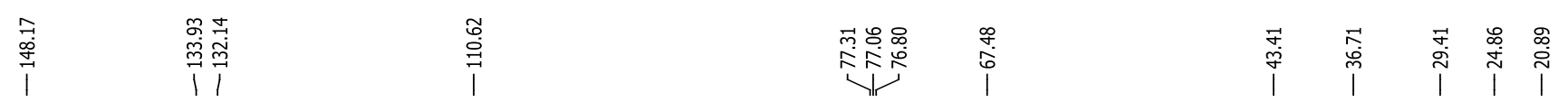

${ }^{13} \mathrm{C} \mathrm{NMR}\left(126 \mathrm{MHz}, \mathrm{CDCl}_{3}\right) \delta 148.17(\mathrm{C}), 133.93(\mathrm{CH}), 132.14(\mathrm{CH}), 110.62\left(\mathrm{CH}_{2}\right), 67.48$

$(\mathrm{C}), 43.41(\mathrm{CH}), 36.71\left(\mathrm{CH}_{2}\right), 29.41\left(\mathrm{CH}_{3}\right), 24.86\left(\mathrm{CH}_{2}\right), 20.89\left(\mathrm{CH}_{3}\right)$.
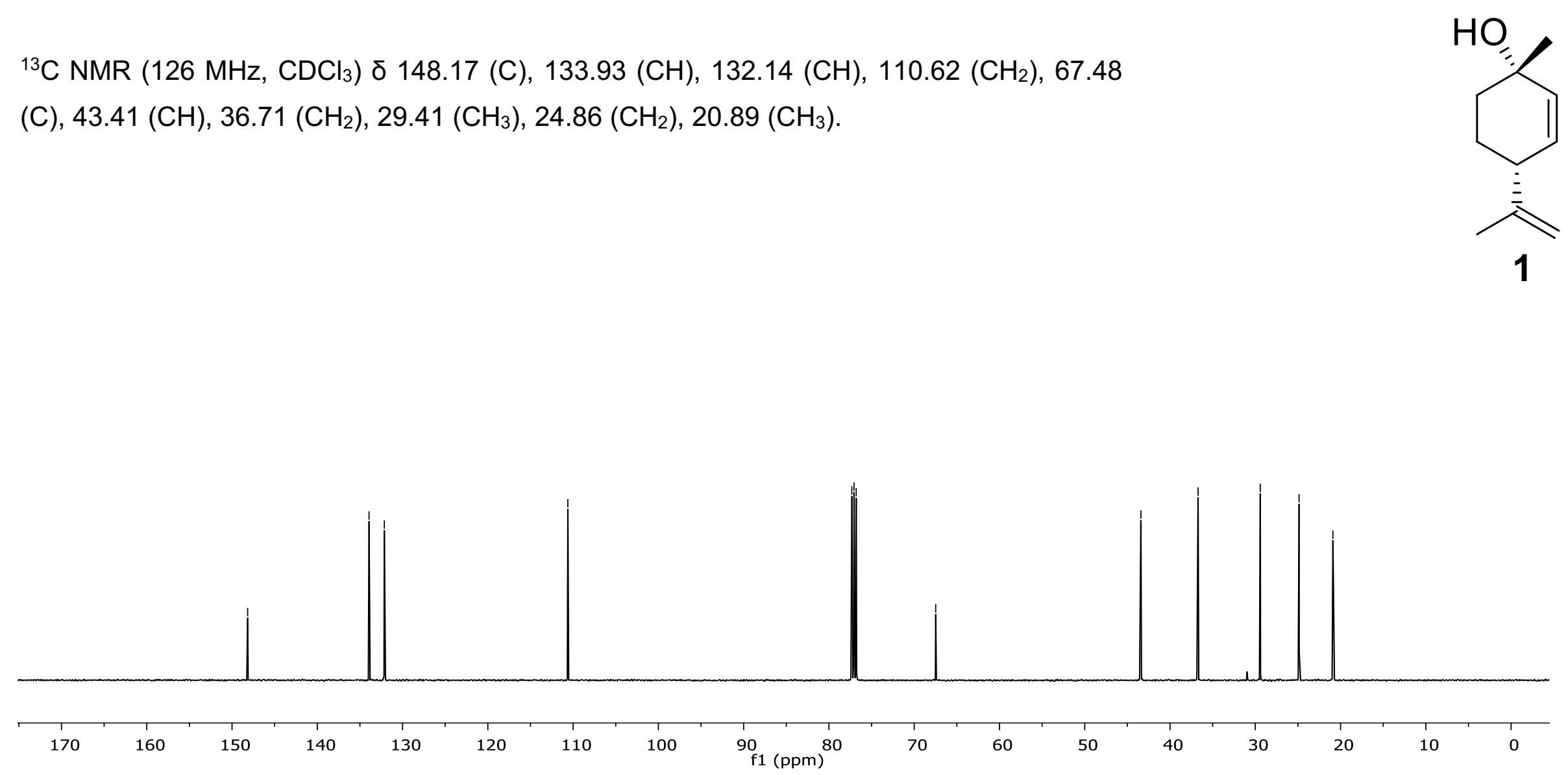

Figure $\mathrm{S} 17{ }^{13} \mathrm{C}$ NMR spectra of $p$-mentha-2,8-dien-1-ol (1) in $\mathrm{CDCl}_{3}$ 


\section{1}

(1) de Souza, J. M.; Brocksom, T. J.; McQuade, D. T.; de Oliveira, K. T. Continuous Endoperoxidation of Conjugated Dienes and Subsequent Rearrangements Leading to $\mathrm{C}-\mathrm{H}$ Oxidized Synthons. J. Org. Chem. 2018, 83 (15), 7574-7585. https://doi.org/10.1021/acs.joc.8b01307.

(2) de Souza, A. A. N.; Silva, N. S.; Müller, A. V.; Polo, A. S.; Brocksom, T. J.; de Oliveira, K. T. Porphyrins as Photoredox Catalysts in Csp $2-\mathrm{H}$ Arylations: Batch and Continuous Flow Approaches. J. Org. Chem. 2018, 83 (24), 15077-15086. https://doi.org/10.1021/acs.joc.8b02355. 